\title{
Automatic Injection System Device
}

National Cancer Institute

\section{Source}

National Cancer Institute. Automatic Injection System Device. NCI Thesaurus. Code C50317.

A system designed to pump a gas or liquid into a space or environment without outside intervention. 